\title{
For better resuscitation in head up position cardiopulmonary resuscitation: using echocardiography
}

\author{
Euigi Jung, Yu Chan Kye, Chanjong Park, Jungyoup Lee, Jeong Ryel Park, \\ Kwang Ho Lee, Sun Sook Kim, Se Jong Lee, Dongsung Kim, Dongwook Kim \\ Department of Emergency Medicine, Veterans Health Service Medical Center, Seoul, Korea
}

\section{Dear Editor,}

With great interest, we have read the article by Park et al. ${ }^{1}$ published in Clinical and Experimental Emergency Medicine. This article shows that a $30^{\circ}$ angle head-up positioned cardiopulmonary resuscitation (CPR) resulted in a lower 24-hour survival rate and return of spontaneous circulation rate compared with conventional supine positioned CPR. We completely agree that this study was interesting and meaningful for CPR situations where the patient cannot be laid down, such as an elevator. However, we would like to suggest a simple proposal for future experiments.

It is not clear which point of the chest was specifically compressed by the mechanical CPR device in this paper. Pressing on the accurate position of the heart is essential to achieve good quality CPR. The optimal chest compression point, even in the supine position, varies from swine to swine. ${ }^{2}$ Furthermore, because of gravity, the heart sits lower in the chest in the head-up tilt position, compared to the supine position. It is evident that just turning to the left side for an echocardiography can change the position of the heart. Therefore, further investigations that incorporate adjusting chest compression points in the head-up tilt position might be needed.

It is simple and easy to find the position of the heart by using echocardiography. It would be more helpful to use echocardiography before applying the mechanical CPR device. Echocardiography is noninvasive, fast, and easy to perform. In the parasternal long axis view, if the right ventricle is shown at the top center of the screen and the left ventricle is shown beneath the right ventricle, that could be an appropriate chest compression point. ${ }^{3,45}$ The optimal chest compression point might be different in the supine position from the head-up tilt position. From this point of view, echocardiography could have influenced the result of this experiment and suggest the adjusted heart position in the head-up status.

\section{CONFLICT OF INTEREST}

No potential conflict of interest relevant to this article was reported.

\section{REFERENCES}

1. Park YJ, Hong KJ, Shin SD, et al. Worsened survival in the head-up tilt position cardiopulmonary resuscitation in a porcine cardiac arrest model. Clin Exp Emerg Med 2019;6:250-6.

2. Suh GJ, Park J, Lee JC, et al. End-tidal CO(2)-guided automated robot CPR system in the pig:
eISSN: 2383-4625

Received: 27 November 2019 Revised: 30 December 2019 Accepted: 30 December 2019

Correspondence to: Euigi Jung Department of Emergency Medicine, Veterans Health Service Medical Center, 53 Jinhwangdo-ro 61-gil, Gangdong-gu, Seoul 05368, Korea E-mail: euigi.jung@bohun.or.kr ORCID

https://orcid.org/0000-0001-5194-4720

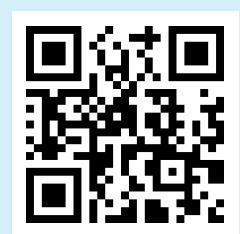

How to cite this article:

Jung E, Kye YC, Park C, Lee J, Park JR, Lee KH, Kim SS, Lee SJ, Kim D, Kim D. For better resuscitation in head up position cardiopulmonary resuscitation: using echocardiography. Clin Exp Emerg Med 2020;7(1):71.

This is an Open Access article distributed under the terms of the Creative Commons Attribution Non-Commercial License (https:// creativecommons.org/licenses/by-nc/4.0/). 
preliminary communication. Resuscitation 2018;127:119-24.

3. Fair J 3rd, Mallin MP, Adler A, et al. Transesophageal echocardiography during cardiopulmonary resuscitation is associated with shorter compression pauses compared with transthoracic echocardiography. Ann Emerg Med 2019;73:610-6.

4 Blanco P, Martinez Buendia C. Point-of-care ultrasound in cardiopulmonary resuscitation: a concise review. J Ultrasound 2017;20:193-8.

5. Blaivas M. Transesophageal echocardiography during cardiopulmonary arrest in the emergency department. Resuscitation 2008;78:135-40. 